\title{
Landscape composition and configuration affect the abundance of the olive moth (Prays oleae, Bernard) in olive groves
}

\author{
María Villa $^{\mathrm{a}}$, Sónia A.P. Santos ${ }^{\mathrm{b}, \mathrm{c}}$, José Paulo Sousa ${ }^{\mathrm{d}}$, Alberto Ferreira ${ }^{\mathrm{d}}$, Pedro Martins da Silva ${ }^{\mathrm{d}, \mathrm{e}}$, \\ Isabel Patanita ${ }^{\mathrm{f}}$, Marta Ortega ${ }^{\mathrm{g}}$, Susana Pascual ${ }^{\mathrm{h}}$, José Alberto Pereira ${ }^{\mathrm{a}, *}$ \\ ${ }^{a}$ Centro de Investigação de Montanha (CIMO), Escola Superior Agrária, Instituto Politécnico de Bragança, Campus Sta Apolónia, 5300-253, Bragança, Portugal \\ ${ }^{\mathrm{b}}$ CIQuiBio, Barreiro School of Technology, Polytechnic Institute of Setúbal, Rua Américo da Silva Marinho, 2839-001, Lavradio, Portugal \\ ${ }^{\mathrm{c}}$ Linking Landscape, Environment, Agriculture and Food (LEAF), Instituto Superior de Agronomia, Universidade de Lisboa, Tapada da Ajuda, 1349-017, Lisboa, Portugal \\ ${ }^{\mathrm{d}}$ Centre for Functional Ecology, Department of Life Sciences, University of Coimbra, Calçada Martim de Freitas, 3000-456, Coimbra, Portugal \\ ${ }^{\mathrm{e}}$ Centre for Ecology, Evolution and Environmental Change, Faculty of Sciences, University of Lisbon, Rua Ernesto de Vasconcelos Ed. C2-5 ${ }^{\circ}$ Floor, Campo Grande, 1749- \\ 016, Lisbon, Portugal \\ ${ }^{\mathrm{f}}$ School of Agriculture, Polytechnic Institute of Beja, Departamento de Biociências, Rua Pedro Soares, 7800-295, Beja, Portugal \\ ${ }^{\mathrm{g}}$ Ecology Department, Faculty of Biological Sciences, Universidad Complutense de Madrid, C/ José Antonio Novais n॰2, 28040, Madrid, Spain \\ ${ }^{\mathrm{h}}$ Entomology Group, Plant Protection Department, Instituto Nacional de Investigación y Tecnología Agraria y Alimentaria (INIA), Carretera de La Coruña Km 7,5, 28040, \\ Madrid, Spain
}

\section{A R T I C L E I N F O}

\section{Keywords:}

Conservation biological control

Multi scale analysis

Crop management

Perennial crops

Generalized additive mixed models

\begin{abstract}
A B S T R A C T
Landscape and crop management are important concepts for conservation biological control as they can influence the abundance of natural enemies. In this work we accomplished a multi-scale study focused on the effect of landscape structure and crop management on the olive moth, Prays oleae (Bernard), an important pest of the olive tree (Olea europaea L.). The olive moth was collected in different olive groves managed under organic farming and integrated production and surrounded by different landscape structures. Generalized additive mixed models were used to analyze the response of the pest to (i) landscape composition and configuration indices, (ii) the management system and (iii) pesticides applications at different scales. Results indicated that the landscape composition, through the effect of the Simpson's diversity index, negatively influenced $P$. oleae abundance and that the effect was evident at larger scales. Also, the landscape configuration negatively affected $P$. oleae at larger scales. However, neither the crop management system nor the pesticide applications affected $P$. oleae abundance. This study emphasizes that the preservation or implementation of diverse and complex landscapes can contribute to maintain lower population levels of $P$. oleae when compared with homogenous landscape areas.
\end{abstract}

\section{Introduction}

The olive tree (Olea europaea L.) is a perennial crop with increasing interest all over the world (FAOSTAT, 2019). Nowadays, it is cultivated in all regions with suitable climatic conditions and its products have an increasing economic relevance (Bartolini and Petruccelli, 2002; FAOSTAT, 2019). Traditionally managed olive groves are usually surrounded by a complex landscape mosaic which includes different patch types, such as scrublands, grasslands, forest areas or other perennial crops (e.g., almond trees and vineyards) (Fleskens, 2007). However, in recent years, strong market pressure has encouraged growers to intensify the production, involving some impacts such as the simplification of the agricultural landscape, the presence of pesticide residues in soils, vegetation and olives, the degradation of natural resources, the loss of biodiversity and the development of insecticide resistance by pests (Hawkes et al., 2005; Tscharntke et al., 2007; Tous et al., 2011; Samnegårdg et al., 2018). As a consequence, ecosystem services such as biological control, pollination and landscape values, may be endangered (Koh and Holland, 2015; Teixeira Saturni et al., 2016).

This crop is attacked by several pests, such as the olive moth, Prays oleae (Bernard), which causes important production losses (Bento et al., 2001). The olive moth is a microlepidoptera belonging to the Praydidae family. It has three generations a year and larvae feed on different olive tree organs. Adults of the phyllophagous generation emerge in the beginning of the spring, lay the eggs of the anthophagous generation on the floral buttons and the newly hatched larvae feed on the olive tree flowers until pupation. Adults emerge at the end of the spring and lay the eggs of the carpophagous generation on the calyx of the young olive

\footnotetext{
* Corresponding author.

E-mail address: jpereira@ipb.pt (J.A. Pereira).
} 
fruits. Larvae bore into the olive stone and feed on the seed. In the end of the summer and in the beginning of the autumn, adults emerge and lay the eggs of the phyllophagous generation on the olive leaves. Larvae of the phyllophagous generation dig galleries and feed on leaves, where they overwinter till the beginning of the spring (Arambourg, 1986).

Several studies have addressed the potential effect of the landscapescale (i.e., landscape structure) and/or local-scale (i.e., management practices within field) on different functional groups, such as pests and their natural enemies, suggesting that the complexity, heterogeneity and low impact practices can contribute to maintaining and enhancing the biological control of pests (Bianchi et al., 2006; Tscharntke et al., 2007; Zhao et al., 2016; Lefebvre et al., 2016; Porcel et al., 2018). Paredes et al. (2013a) showed that the abundance of natural enemies was, in general, more influenced by herbaceous and large woody vegetation adjacent to the crop than by small woody vegetation. Martins da Silva et al. (2017) found that carabid species varied with the specific management practices in the olive grove as well as with local and linear features around the groves. However, Albertini et al. (2016) did not find significant correlations between the occurrence of natural areas close to the olive groves and the abundance of predaceous Coleoptera in the crop area. Other landscape characteristics, such as the landscape connectivity, positively affected the parasitism rate of the olive fruit fly Bactrocera oleae (Rossi) (the key pest of the olive tree) (Boccaccio and Petacchi, 2009). For pests, Paredes et al. (2013b) found lower abundances of the olive psyllid Euphyllura olivina (Costa) (an occasional pest of the olive tree) and $P$. oleae in olive groves surrounded by non-crop vegetation areas of herbaceous and woody vegetation, as well as in olive groves integrating small patches of woody vegetation. Ortega and Pascual (2014) showed that the reduction of the abundance of B. oleae was correlated with the landscape complexity and Ortega et al. (2016) found that the relationships between the landscape structure and the abundance of $B$. oleae depended on the spatial scale. Sáenz Posada (2013) showed that $P$. oleae abundance decreased in more diverse landscapes and increased in more irregular shaped patches located in southern Spain.

At a local scale, i.e., considering the effect of the olive crop management on arthropods, usually organic farming benefited natural enemies. For example, organic olive groves presented higher abundance and richness of spiders in the canopy, higher predation rates of $B$. oleae pupae and larger and more complex arthropod food-webs offering better conditions for biological pest control than conventional groves (Picchi et al., 2016, 2017; Morente et al., 2018). Moreover, Villa et al. (2016) determined that low impact agricultural practices favored $P$. oleae parasitism.

In this context, our objective was to analyze the variation of $P$. oleae abundance in olive groves under different management systems (organic and integrated) and across an increasing gradient of landscape simplification at different landscape scales. We hypothesized that: (i) more diverse landscape composition and (ii) more complex landscape configuration negatively influenced $P$. oleae abundance and (iii) the management system affected $P$. oleae abundance.

\section{Material and methods}

\subsection{Study sites}

The study was conducted in 2011 in 17 olive groves, nine were located in the area surrounding Mirandela municipality, in Trás-osMontes region, northeastern Portugal and eight were located in the area surrounding Beja municipality, in Alentejo region, south of Portugal. Both regions are typically Mediterranean (characterized by hot and dry summers and mild and moist winters) (Rundel et al., 2016). The study sites were in the same climatic zone in both regions, providing similar site conditions in terms of mean annual rainfall (about $571 \mathrm{~mm}$ in Beja and $524 \mathrm{~mm}$ in Mirandela) and temperature (the mean maximum temperature is $22.5^{\circ} \mathrm{C}$ in Beja and $22.7^{\circ} \mathrm{C}$ in Mirandela and the mean minimum temperature is $10.4{ }^{\circ} \mathrm{C}$ in Beja and $9.6^{\circ} \mathrm{C}$ in Mirandela) (IPMA, 2019). The mean altitude is $196 \mathrm{~m}$ in Beja and $393 \mathrm{~m}$ in Mirandela.

The study areas in Alentejo were in average $18 \mathrm{~km}$ apart $(2 \mathrm{~km}$ minimum and $45 \mathrm{~km}$ maximum) and in Trás-os-Montes $5 \mathrm{~km}$ apart ( $2 \mathrm{~km}$ minimum, $15 \mathrm{~km}$ maximum). Main characteristics of the selected olive groves are presented in Appendix A (Table A.1 and Table A.2). From the 17 study areas, eight represented organic farming systems and nine were olive groves managed under integrated production. Fungicides and insecticides applied in each grove are shown in Appendix A (Table A.3 and Table A.4). The landscape surrounding the central sampling area in each olive grove ranged from heterogeneous landscape with small surrounding patches to homogeneous landscape with large areas of super-intensive olive groves.

\subsection{Sampling of $P$. oleae}

Three delta traps placed $50 \mathrm{~m}$ apart and baited with $P$. oleae sex pheromone (Z)-7-tetradecenal (Biosani, Palmela, Portugal) were installed in a central area of each olive grove. The traps were hung on olive tree branches (at about $2 \mathrm{~m}$ height). Captures were recorded on a weekly basis from April to December 2011.

\subsection{Landscape metrics}

Four circular areas (buffer), with radii of 500, 600, 750 and $1000 \mathrm{~m}$, were nested around each study site (Fig. 1). The largest buffer did not overlap among the different fields sites in order to avoid spatial autocorrelation. Land-use classes occurring across study sites were obtained from "Carta de Uso e Ocupação do Solo de Portugal Continental para 2007" (COS2007). The different types of land use and their percentage cover (area) within each circle were assessed to determine the landscape composition and configuration. Land-use classes considered to calculate the landscape indices were: artificial areas (A), deciduous woods (BD), evergreen woods (BE), other crops (C), grasslands with disperse oaks $(\mathrm{DH})$, conifers $(\mathrm{F})$, scrublands $(\mathrm{M})$, olive crops $(\mathrm{O})$, grassland $(\mathrm{P})$, river $(\mathrm{RB})$, water $(\mathrm{W})$.

At the class level, the most common land uses in the study regions, i.e., (i) the percentage of olive crops (O), (ii) the percentage of other crops (C) and (iii) the percentage of scrublands (M), were selected for further analysis. At the landscape level the following metrics were considered: (i) number of patches (NP): number of patches within the buffer; (ii) mean patch size (MPS): mean area of patches (hectares); (iii) patch size coefficient of variation (PSCV): measurement of the variability among patches as a percentage of the mean patch size (it results from the patch size standard deviation (hectares) divided by the mean patch size (hectares) and multiplied by 100); (iv) the total edge (TE): total edge length of all patch types (meters); (v) mean patch edge (MPE): average amount of edge per patch (meters/patch) (vi) mean shape index (MSI): quantifies the patch shape by measuring the average patch shape as the sum of the perimeter of each patch divided by the square root of patch area (ha) for all patches, divided by the number of patches; (vii) area weighted mean shape index (AWMSI): weights MSI according to the size of the patches, weighting more heavily larger patches than smaller; (viii) the mean perimeter-area ratio (MPAR): quantifies the shape complexity, resulting from the sum of each patch perimeter/area ratio divided by the number of patches (meters/ hectare); (ix) mean patch fractal dimension (MPFD): quantifies the degree of complexity of the landscape by measuring the complexity of a polygon by relating perimeter and area; (x) area-weighted mean patch fractal dimension (AWMPFD): weights MPFD according to the patches size; (xi) Shannon`s diversity index (SDI): quantifies the landscape composition (more sensitive to richness than evenness); and (x) Simpson's diversity index (SEI): quantifies the landscape composition (less sensitive to richness and more to common patches), and it represents the probability that any types selected at random would be different types (McGarigal and 


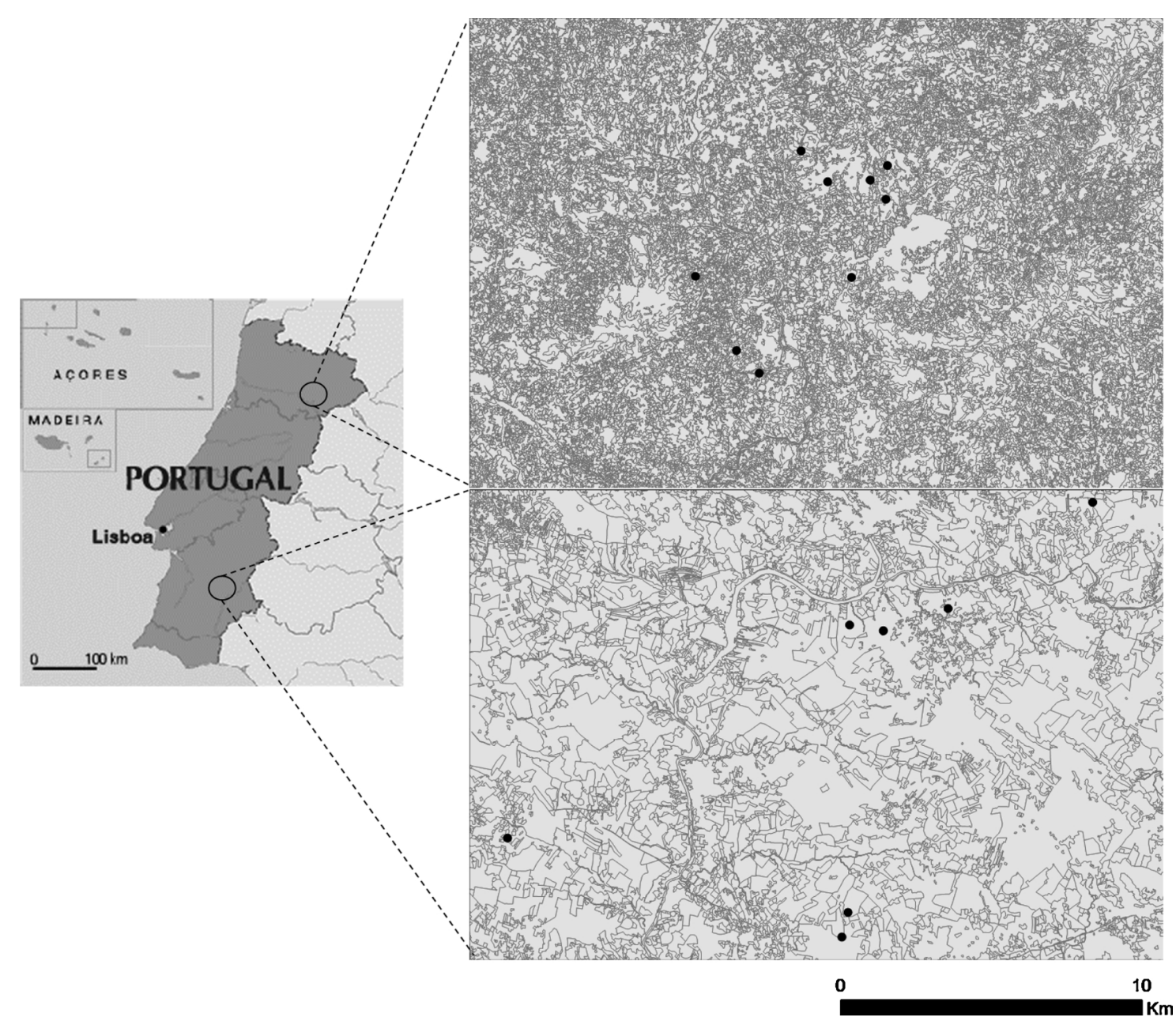

Fig. 1. Location of the study areas. On the left, the study areas at the north and south of Portugal are shown. At the right the location of the sampled olive orchards in the north and south of Portugal are shown.

Marks, 1995). The software Patch Analyst for ArcGIS, version 9.3.1 (ESRI, Redlands, California) was used to calculate landscape metrics.

\subsection{Data analysis}

All analyses were performed using R software version 3.5.1 (R Core Team, 2018).

\subsubsection{Landscape description}

Values of the landscapes indices were plotted against the orchards in the south and north of Portugal at different scales $(500 \mathrm{~m}, 600 \mathrm{~m}, 750 \mathrm{~m}$ and $1000 \mathrm{~m}$ buffers) in order to describe the landscapes.

To synthetize that information a principal component analysis (PCA) based on the correlation matrix of the landscape indices was performed and presented as supplementary material (Fig. A.1), the correlation biplot of the two first PCs were represented in order to visualize the landscapes for each PCA. PCAs were performed using the function prcomp.

\subsubsection{Influence of the landscape variables on P. oleae abundance}

Four separated generalized additive mixed models (GAMMs), one for each scale $(500 \mathrm{~m}, 600 \mathrm{~m}, 750 \mathrm{~m}$ and $1000 \mathrm{~m})$, were performed to analyze $P$. oleae response to landscape variables along the sampling period at the different scales. For that, gamm4 function from "gamm4" package (Wood and Scheipl, 2016) in R was used.

Prior to run the model, explanatory landscape variables were selected using the Variance Inflation Factor (VIF) criteria to avoid collinearity. Collinearity between explanatory variables is associated with several risks related with the inaccuracy of the model, the decrease of the statistical power or the exclusion of significant explanatory variables during the model selection (see Graham (2003) for further details). This is particularly relevant in landscape studies: some landscape or class metrics may be partially or completely redundant. Sometimes they quantify a similar or identical aspect of landscape pattern or some aspects of landscape pattern under investigation may be statistically correlated (McGarigal and Marks, 1995). Several methods have been addressed to minimize the risks (e.g., Graham, 2003; Zuur et al., 2010), although all of them involve a certain degree of subjectivity. In this study landscape indices with minimum collinearity were selected. The metrics with the highest VIF were sequentially dropped until all VIFs were lower than a determined threshold. Some authors recommend thresholds of 10 and others recommend a more restrictive threshold (for example, VIF < 3) (Graham, 2003 and references therein, Zuur et al., 2010 and reference therein). Following Zuur et al. (2010) only explanatory variables with VIF $<3$ were used (maximum VIF was 1.75, 1.82, 2.18 and 2.85 in GAMM for 500, 600, 750 and $1000 \mathrm{~m}$ buffers respectively). The variable latitude (Y), as continuous variable, was maintained in all cases because of its potential importance in explaining differences between northern and southern olive orchards. After the selection of explanatory variables only the potential relevant interactions were included in the models in order to avoid convergence problems. Thus, the interactions between latitude and $\mathrm{O}(\mathrm{Y}: \mathrm{O})$, due to the relevance of the olive orchard for this study, and between latitude and SDI (Y:SDI) or SEI (Y:SEI), due to the fact that 
sites in the north and in the south of the country differ in landscape diversity and is amply referred as important in the literature (e.g., Bianchi et al., 2006), were studied. The interactions NP:O, NP:M, and between the metrics AWMSI and PSCV (both resulting from ratios where the denominator is MPS), and MPS were studied to analyze their marginal effects.

In each of the four models, explanatory variables and interaction previously selected were used as fixed factors and explanatory variables were centered. The location of the orchards was used as a random effect. Due to the non-linear nature of the $P$. oleae abundance along the year, the Julian days variable was fitted as a smoother. The negative binomial distribution was used to account for overdispersion. Since gamm4 does not estimate the dispersion parameter, different values of the dispersion parameter were applied to all the models until the lowest value of Akaike Information Criterion (AIC) was encountered. Then, that dispersion parameter was used in the models. Backward selection using the AIC was used to find the optimal model (AIC calculated for these models are comparable once all the models were fitted with gamm 4 function and therefore AIC calculation follows the same criterions for all models). The models were validated by plotting residuals versus fitted values to assess the absence of patterns in the residuals and a generalized additive model (GAM) was fitted with the residuals as response variable and a smooth of the predicted values as explanatory variable to detect non-linear patterns. A plot of the residuals versus each covariate in the model and not in the model was used to investigate model misfit and a GAM was fitted with the residuals as response variable and a smooth of each predictor in the GAMM as explanatory variable to detect non-linear patterns (Zuur et al., 2014).

In summer, $P$. oleae is at larval stage, therefore, captures of $P$. oleae adults were zero or very low (lower than 5 ) during several weeks. In this work, the interest was focused in $P$. oleae adults, therefore, those dates were excluded from data analyses.

\subsubsection{Influence of management system on $P$. oleae abundance and pesticides applications for pest control}

Two GAMMs were performed. The first one analyzed the $P$. oleae response to the management system of the orchards (integrated or organic) along the sampling period. Given that management system is an artificial classification defined by individual management practices which can affect arthropod populations and pesticide application can be the most impacting one, a second GAMM analyzed the application of pesticides for pest control (application or no application) along the sampling period. The response variable was $P$. oleae abundance and the explanatory variables were the management system or the application/ absence of application. The location of the olive groves was used as a random effect and the Julian days were fitted as a smoother in both cases. The negative binomial distribution was used to account for overdispersion. Model fit and validation was performed as in the previous section.

\section{Results}

\subsection{Landscapes description}

The descriptive statistical analysis showed that the distributions of the landscape variables in the sampled olive orchards were similar for each scale (Fig. A.1). About the landscape composition, the study sites in the north of Portugal were generally more diverse and had a higher percentage of scrublands and in the south were more variable (Fig. 2). Concerning the landscape configuration, Fig. 2 shows that the northern sites had larger number of patches (NP), mean shape indices (MSI), mean patch fractal dimensions (MPFD) and variants weighted by area (AWMSI and AWMPFD) but smaller mean patch sizes (MPS) and mean patch edges (MPE). This indicates the occurrence of more irregular and complex landscapes in the northern study sites independently of the patch size.

Considering the different scales $(500 \mathrm{~m}, 600 \mathrm{~m}, 750 \mathrm{~m}$ and $1000 \mathrm{~m}$ ), the position of the study sites and landscape variables were similar in each biplot (Fig. A.1). Study sites were grouped by their location (in the north or in the south of Portugal) indicating the occurrence of different landscape compositions and configurations in each latitude (Fig. A.1).

Additionally, olive orchards presented bigger MPS than other land uses in the north. In the south, MPS was bigger for olive orchards followed by other crops, evergreen woods and grasslands with disperse oaks in the south (Fig. 3).

\subsection{Selection of landscape variables for GAMMs}

After dropping the metrics with higher VIFs, the selected metrics for GAMMs in each scale were: (i) JD for $500 \mathrm{~m}$; (ii) JD and NP for $600 \mathrm{~m}$; (iii) JD, Y and SEI for $750 \mathrm{~m}$; and (iv) JD, Y, SEI and MSI for $1000 \mathrm{~m}$.

\subsection{Influence of the landscape variables on P. oleae abundance}

The GAMMs for $P$. oleae response to the variables of the landscape configuration and composition at the different scales with the Julian days, showed that $P$. oleae abundance varied throughout the year according to the three generations of the pest (Fig. A.2), being the smooth function of the Julian days highly significant in all models (Table 1). The predictions were similar for the four models (Fig. 4 for visualizing the model at $500 \mathrm{~m}$ and Fig. A.3, A.4 and A.5 for visualizing the magnitude and direction of the significant effects). No misfit was found in the validation of the final models. Model (Fig. 4) and over-dispersion parameters (between 0.82 and 0.83 for all models) showed a slight overfit. Some heterogeneity was shown in the four residuals vs. fitted values plots. Therefore, despite the observed significances, higher $p$ values should be considered with care. However, the GAM fitted with the residuals as response variable and the smooth of the predicted values as explanatory variable did not detect non linearity $(500 \mathrm{~m}$ : $F=0.658, \quad$ edf $=1.680, \quad p$-value $=0.557 ; \quad 600 \mathrm{~m}: \quad F=1.152$, edf $=1.941, \quad p$-value $=0.374 ; \quad 750 \mathrm{~m}: \quad F=1.021, \quad$ edf $=1.853, \quad p$ value $=0.420 ; 1000 \mathrm{~m}: F=0.704$, edf $=1.697, p$-value $=0.54)$.

In relation to the landscape composition (Table 1), the interaction between the number of patches and scrublands (NP:M) as well as the main effect of scrublands (M), latitude $(\mathrm{Y})$ and other cultures $(\mathrm{C})$ were dropped from the model fitted at $500 \mathrm{~m}$. At $600 \mathrm{~m}$, the interaction between the number of patches and scrublands (NP:M) and between latitude and the Simpson's diversity index (Y:SEI.), as well as the main effects of $Y$, SEI, $M$ and $C$ were dropped from the model. At $750 \mathrm{~m} \mathrm{M}$ and $\mathrm{C}$ were dropped from the model but the interaction Y:SEI corresponded to a significant decrease of $P$. oleae abundance. At $1000 \mathrm{~m}, \mathrm{M}$ and $\mathrm{C}$ were dropped from the model and $P$. oleae abundance significantly decreased with the interaction Y:SEI, These results indicate that at smaller scales $(500 \mathrm{~m}$ and $600 \mathrm{~m}), P$. oleae abundance was not affected by the landscape composition. However, in larger scales (750 and $1000 \mathrm{~m}$ ), $P$. oleae abundance decreased with the increase of latitude together with the landscape diversity.

Considering the landscape configuration, the main effect of NP was dropped from the model at $500 \mathrm{~m}$ but at $600 \mathrm{~m}$ P. oleae decreased with NP. At $750 \mathrm{~m}$ none configuration variable was included in the model. At 1000 MPAR was dropped from the model but $P$. oleae decreased with the increase of the mean shape index (MSI). These results indicate that only at the lowest scale $(500 \mathrm{~m}), P$. oleae did not decreased with the landscape complexity.

\subsection{Influence of management system and pesticide applications on P. oleae abundance}

According to the GAMMs, neither the management system nor pesticide applications affected $P$. oleae abundance (management system: estimate $=0.092 ; \mathrm{SE}=0.170 ; Z=0.542 ; p$-value $=0.588$; pesticide applications: estimate $=0.173 ; \mathrm{SE}=0.162 ; Z=1.071 ; p$ value $=0.284$ ). No misfit was found in the validation of the final 

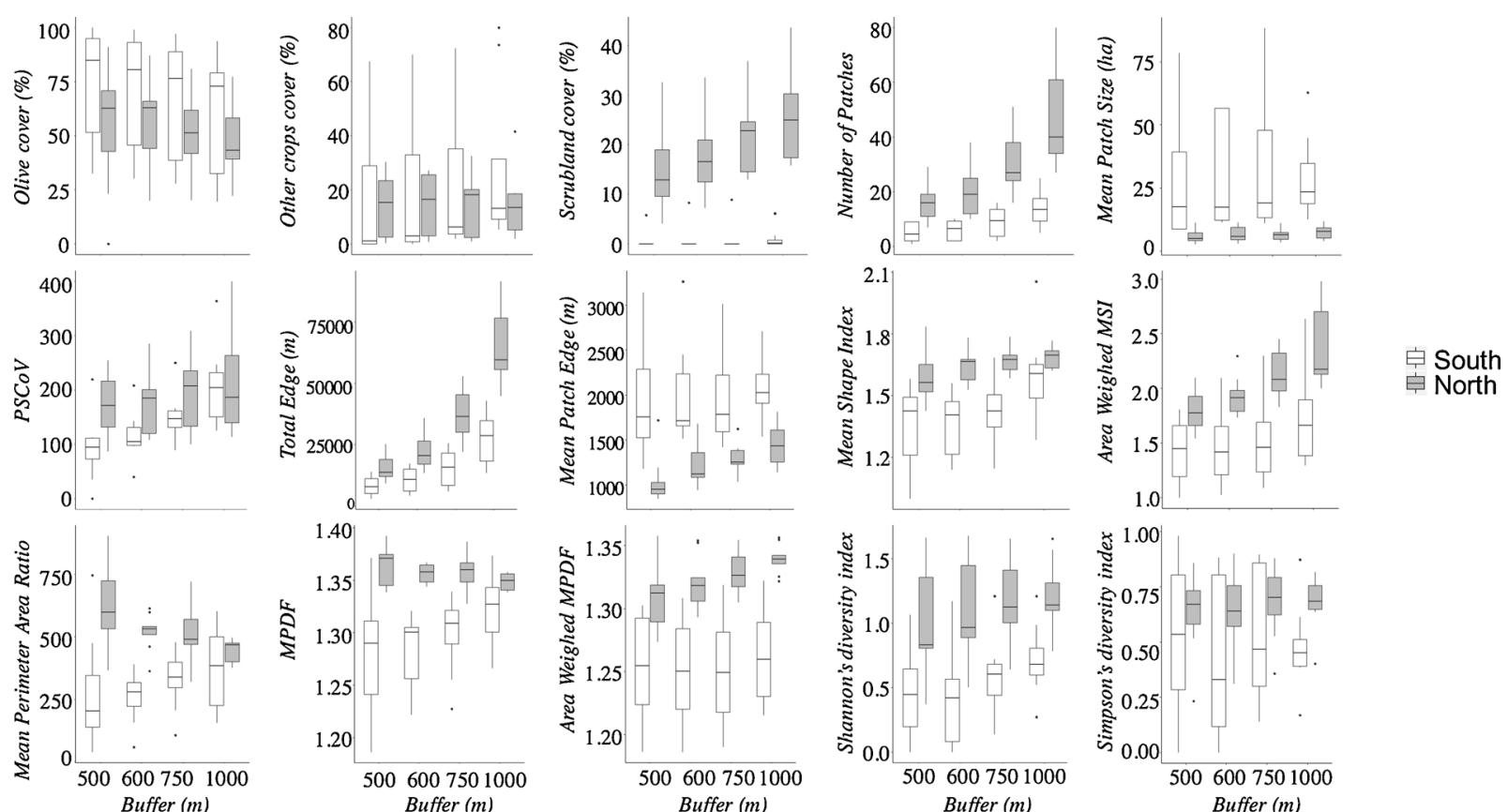

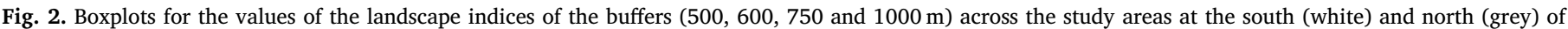

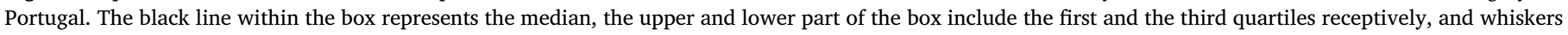
are the highest and lowest values within $95 \%$ confident interval of the median. Points represent values outside the $95 \%$ the confident interval.

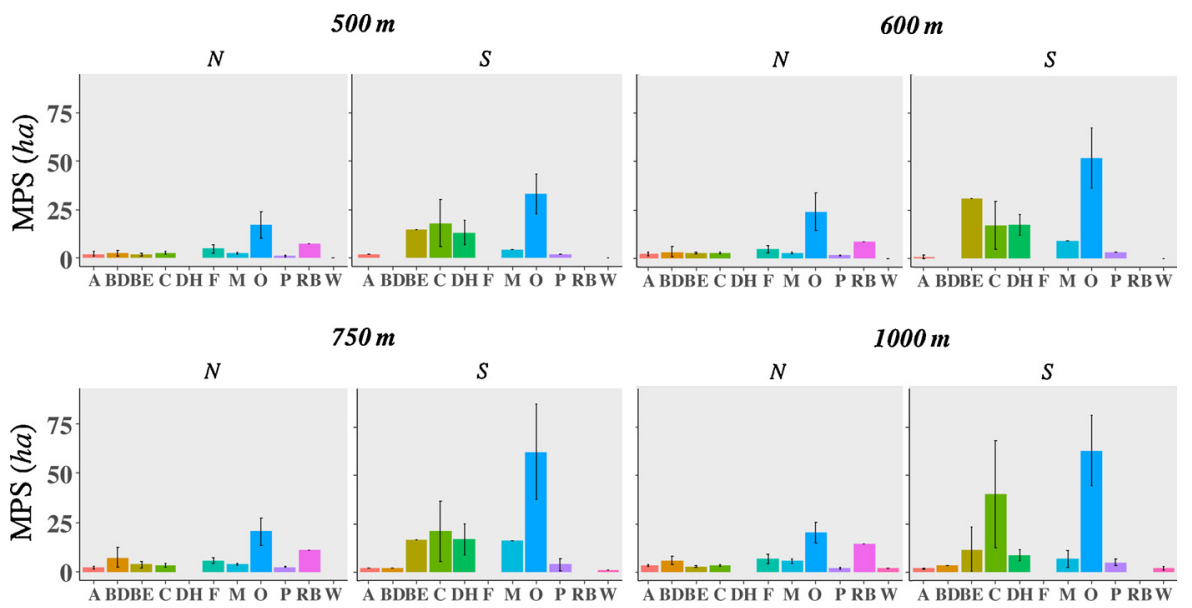

Fig. 3. Mean Patch Size (MPS) \pm SE (ha) of the different land uses at the four buffer sizes $(500 \mathrm{~m} ; 600 \mathrm{~m}$; $750 \mathrm{~m} ; 1000 \mathrm{~m}$ ). Land uses: artificial areas (A), deciduous woods (BD), evergreen woods (BE), other crops (C), grasslands with disperse oaks (DH), conifers (F), scrublands $(\mathrm{M})$, olive crops $(\mathrm{O})$, grassland $(\mathrm{P})$, river (RB), water (W).

Table 1

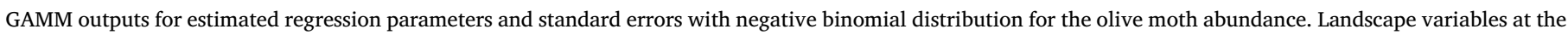

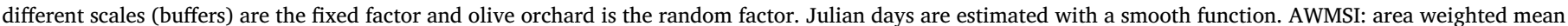

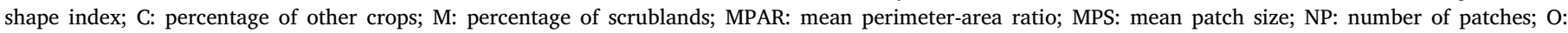

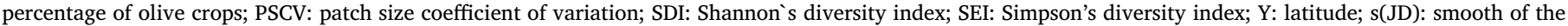
Julian days; edf: effective degrees of freedom of the smother.

\begin{tabular}{|c|c|c|c|c|c|c|c|c|c|c|c|c|c|c|c|c|c|c|c|}
\hline \multicolumn{5}{|c|}{ GAMM for $500 \mathrm{~m}$ buffers } & \multicolumn{5}{|c|}{ GAMM for $600 \mathrm{~m}$ buffers } & \multicolumn{5}{|c|}{ GAMM for $750 \mathrm{~m}$ buffers } & \multicolumn{5}{|c|}{ GAMM for $1000 \mathrm{~m}$ buffers } \\
\hline Fixed effect & Estimate & SE & $z$-value & $p$-value & \begin{tabular}{|l|} 
Fixed \\
effect
\end{tabular} & Estimate & SE & $z$-value & $p$-value & $\begin{array}{l}\begin{array}{l}\text { Fixed } \\
\text { effect }\end{array} \\
\end{array}$ & Estimate & SE & $z$-value & $p$-value & $\begin{array}{l}\text { Fixed } \\
\text { effect }\end{array}$ & Estimate & SE & $z$-value & $p$-value \\
\hline \multirow[t]{5}{*}{ Intercept } & 5.56 & 0.15 & 38.27 & $<0.001$ & Intercept & 4.653 & 0.082 & 56.443 & $\begin{array}{c}<001 \\
\end{array}$ & Intercept & 4.726 & 0.073 & 64.630 & $<0.001$ & Intercept & 4.761 & 0.081 & 58.938 & $<0.001$ \\
\hline & & & & & NP & -0.152 & 0.076 & -2.006 & 0.045 & $\mathrm{Y}$ & -0.041 & 0.069 & -0.602 & 0.547 & $\mathrm{Y}$ & 0.006 & 0.078 & 0.083 & 0.934 \\
\hline & & & & & & & & & & SEI & -0.107 & 0.080 & -1.327 & 0.184 & SEI & -0.085 & 0.084 & -1.017 & 0.309 \\
\hline & & & & & & & & & & $\mathrm{Y}: \mathrm{SEI}$ & -0.246 & 0.079 & -3.097 & 0.002 & MSI & -0.136 & 0.067 & -2.033 & 0.042 \\
\hline & & & & & & & & & & & & & & & $\mathrm{Y}: \mathrm{SEI}$ & -0.198 & 0.082 & -2.402 & 0.016 \\
\hline Smooth term & edf & Ref.df & Chi.sq & $p$-value & $\begin{array}{l}\begin{array}{l}\text { Smooth } \\
\text { term }\end{array} \\
\end{array}$ & edf & Ref.df & Chi.sq & $p$-value & $\begin{array}{l}\text { Smooth } \\
\text { term }\end{array}$ & edf & Ref.df & Chi.sq & $p$-value & $\begin{array}{l}\text { Smooth } \\
\text { term }\end{array}$ & edf & Ref.df & Chi.sq & $p$-value \\
\hline $\mathrm{s}(\mathrm{JD})$ & 4.678 & 0.087 & 53.9 & $<0.001$ & s(JD) & 8.78 & 8.78 & 838.9 & $<0.001$ & $\mathrm{~s}(\mathrm{JD})$ & 8.77 & 8.77 & 878.60 & $<0.001$ & $\mathrm{~s}(\mathrm{JD})$ & 8.77 & 8.77 & 873.20 & $<0.001$ \\
\hline $\begin{array}{l}\text { Dropped } \\
\text { variables and } \\
\text { interactions }\end{array}$ & $\mathrm{Y} ; \mathrm{M}$ & IPAR; C; & $\mathrm{M} ; \mathrm{NP} ; \mathrm{NF}$ & & & Y; SEI; M & ; C; NP:N & 4; Y:SEI & & & & $\mathrm{M} ; \mathrm{C}$ & & & & & $\mathrm{R} ; \mathrm{M} ; \mathrm{C}$ & & \\
\hline
\end{tabular}




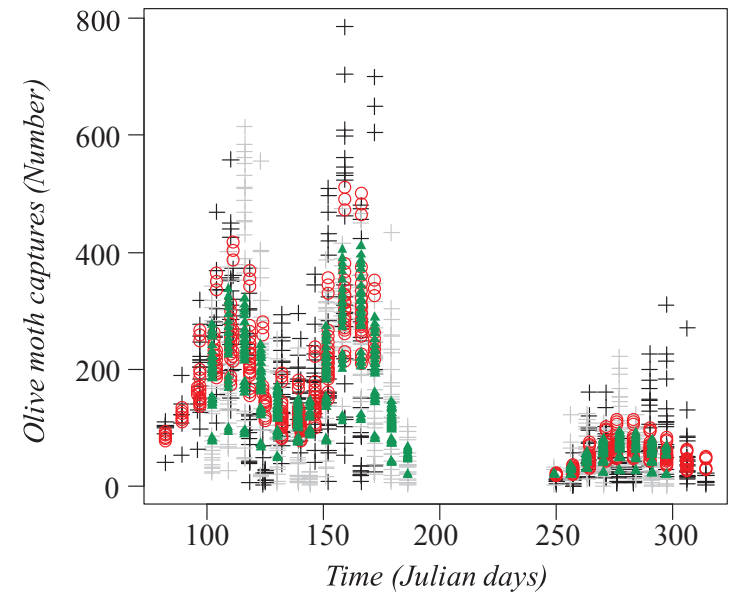

Fig. 4. Observed values $(+)$ and GAMMs predicted values (o, $\boldsymbol{\Delta})$ of olive moth captures (counts) along the year (Julian days) at $500 \mathrm{~m}$ in the southern sites (black and red) and northern sites (grey and green). (For interpretation of the references to colour in this figure legend, the reader is referred to the web version of this article).

models. Some heterogeneity was shown in the residuals vs. fitted values plots. However, the GAMs fitted with the residuals as response variable and the smooth of the predicted values as explanatory variable did not detect non linearity (management system: $F=2.12$, edf $=1.68$, $p$ value $=0.545 ;$ pesticide application: $F=0.74$, edf $=1.724 ; \quad p$ value $=0.519$ )

\section{Discussion}

Several results obtained in this study indicated that $P$. oleae abundance was influenced by (i) the landscape composition and (ii) the landscape configuration but not by (iii) the crop management system or the pesticide applications. Both landscape composition and configuration effects depended on the scale. Additionally, these results reflected the landscape features of the study sites located in the north (more heterogeneous) and in the south (more homogeneous) of the country. Although the northern and southern climatic conditions were similar, the effect of the latitude could be related with differences in temperature and humidity along the year, which are important factors for $P$. oleae development. Low relative humidity $(\mathrm{RH})$ and high temperature can increase the mortality of eggs and young larvae. Montiel Bueno (1981) referred that a $\mathrm{RH}$ of $60 \%$ or lower, together with $30^{\circ} \mathrm{C}$ or higher caused $100 \%$ mortality of eggs, while $70 \% \mathrm{RH}$ and $25{ }^{\circ} \mathrm{C}$ caused $9.8 \%$ mortality of eggs of $P$. oleae. The landscape composition and configuration was different between northern and southern sites, being the northern sites more diverse and complex and the southern more variable. Lastly, the variation of the scale did not result in the variation of landscape indices at both latitudes.

In relation to the landscape composition, $P$. oleae abundance decreased with the increase of the landscape diversity index (SEI) in northern latitudes at larger scales $(750$ and $1000 \mathrm{~m})$. These results are in agreement with Sáenz Posada (2013) that found a negative correlation between Shannon`s diversity index (SDI) and both P. oleae captures and the damages caused by the phyllophagous and anthophagous generations at larger scales $(750 \mathrm{~m}, 1000 \mathrm{~m}, 1500 \mathrm{~m}$ and $2000 \mathrm{~m}$ ) but not at smaller scales $(500 \mathrm{~m}$ and $600 \mathrm{~m})$. However, they found a positive correlation between the SDI and the damages caused by the carpophagous generation. Both studies pointed to a potential decrease of $P$. oleae abundance (mainly the phyllophagous and anthophagous generations) with the increase of the landscape heterogeneity. Paredes et al. (2013b) showed that areas of herbaceous vegetation and areas of woody vegetation within olive groves were correlated with a decrease of $P$. oleae abundance. Moreover, Costa et al. (2020) found that the abundance of $P$. oleae was negatively correlated with the amount of forest cover surrounding olive groves at a $1000 \mathrm{~m}$ scale.

Thus, in relation to our first hypothesis, i.e., P. oleae abundance could be negatively influenced by a highly diverse landscape, we verified that the effect of the landscape composition on $P$. oleae abundance was more noticeable at larger scales. A potential increase of the density of natural enemies with the landscape diversity and with the scrubland/ herbaceous areas may have triggered such reduction. For example, the Anthocoridae Anthocoris nemoralis (Fabricius), which may consume eggs of the anthophagous generation of $P$. oleae, was favored by the occurrence of large woody patches surrounding the olive groves (Paredes et al., 2013a). Similar results were obtained by Boccaccio and Petacci (2009) who showed that the parasitism rate of the olive fly was favored by the occurrence of woodlands (forest and maquis). Also the abundance of the olive fruit fly decreased in the presence of scrublands at the largest scale $(1500 \mathrm{~m})$ (Ortega et al., 2016). Thus, the landscape management could affect other pests, such as the olive fruit fly, as well as natural enemies. However, further studies should focus on clarifying the landscape effects on other pests and their natural enemies.

Our second hypothesis considered that more complex landscape configurations could negatively influence the abundance of $P$. oleae. The decrease of $P$. oleae abundance was correlated with the increase of landscape complexity (NP and MSI) at $600 \mathrm{~m}$ and $1000 \mathrm{~m}$, respectively but not at $500 \mathrm{~m}$. Contrarily, Sáenz Posada (2013) showed that MSI was generally positively correlated with captures and damages of the phyllophagous and anthophagous generations and negatively correlated with the carpophagous generation.

We thirdly hypothesized that the management system affects $P$. oleae abundance. In this study, different management systems (integrated production or organic farming) did not affect the pest. According to the "intermediate landscape complexity hypothesis" the local conservation management is more effective in moderately simple agricultural landscapes, rather than in either cleared (i.e. extremely simplified), where there is no capacity for response, or in highly complex landscapes (which could be the case of the present work), where potential response is already saturated (Tscharntke et al., 2012; Jonsson et al., 2015). Following Tscharntke et al. (2005), the general complex landscape structure of the study areas might compensate the biodiversity loss caused by local management and enhance enemy population densities resulting in biological control benefits. Also, Villa et al. (2016) pointed out the landscape heterogeneity as a potential factor for mitigating some effects of tillage or herbicide application. In agreement, Jonsson et al. (2015) tested the effect of supplementary floral resources in kale Brassica oleracea L. fields surrounded by a gradient of moderately simple to highly complex landscapes on parasitism rates and abundance of aphids (mostly Brevicoryne brassicae L.) and diamondback moths Plutella xylostella L. and found that fields surrounded by moderately simple landscapes responded better to local management. However, Costa et al. (2020) found differences according to the local management, with higher abundances of $P$. oleae in mid-complex olive orchards than in low or high complex orchards, in farms ranked from high complex (traditional orchards with low inputs of agrochemicals) to low complex (intensive farms with several seasonal agrochemicals sprays for pest control). This result was assumed to be related with the level of agrochemicals use, which would increase along the intensification level. In this study, however, pesticide use, which was tested due to its potential impact on pests, did not show effect on $P$. oleae abundance. This result probably was due to the fact that pesticides were used mainly to reduce $B$. oleae populations or some diseases, and applications do not consider the cycle of $P$. oleae, reducing their effectivity. Nevertheless, though management or pesticides did not affect $P$. oleae abundance, they could affect other pests, natural enemies or processes.

Finally, in this study, the complex landscape structure (both composition and configuration) failed to reduce the olive moth at smaller scales, remarking the importance of analyzing multiple spatial scales. 
More works have found that natural habitats failed in supporting biological control. For instance, Muneret et al. (2019) analyzed the effect of a gradient of natural habitats and organic farming land cover on Tortricidae Lobesia botrana (Dennis \& Schiffermüller) and Eupoecilia ambiguella (Hübner), important grape moth pests. These authors found that organic farming enhanced biological control, however increasing the proportion of seminatural habitats had no or negative effects on the potential biological control. In the Colombian Andes, Poveda et al. (2012) found that simplified landscapes (with high percentage of cropped land and low habitat-type diversity) encouraged the presence of the potato moth Tecia solanivora (Povolný), but reduced the richness and abundance of other herbivores and their natural enemies. Some hypotheses can explain the causes of those failures (see Tscharntke et al., 2016 for more details). In the present study, other processes, such as intraguild predation among natural enemies could constrain pest control (Martin et al., 2013). Also mortality during dispersion could be more evident at larger scales. This parameter has been previously pointed out as being related with the effect of landscape configuration indices on B. oleae abundance (Ortega et al., 2016) and has been amply studied in some generalist natural enemies, such as for the pre-ovipository migration flights of chrysopids (Duelli, 2001). However, little is known about $P$. oleae's dispersion, such as barriers and limitations or flight distances and periods of dispersion. In the present study, diversity of land uses, rather than percentage of scrublands (as percentage of natural habitats), resulted in a pest abundance reduction. This highlights the importance of analyzing several landscape variables for measuring complexity, which could lead to a deeper understanding of the ecological processes in agroecosystems. In addition, inter-annual variation may alter conclusions about patterns in ecological processes and arthropods abundance (Villa et al., 2016; Paredes et al., 2013b; Plećaš et al., 2014). Similarly, long term investigations are key to obtain reliable management recommendations.

In sum, in this study, a decrease of $P$. oleae abundance was correlated with the landscape composition, particularly with landscape diversity, and with landscape configuration at larger scales. The latitude showed to be determinant for the number of $P$. oleae captures at larger scales and the management system and pesticide applications effects might have been mitigated by the effects of landscape structure, showing the importance of landscape management. These factors should be considered when designing strategies for controlling pests in olive orchards.

\section{Declaration of Competing Interest}

The authors declare that they have no known competing financial interests or personal relationships that could have appeared to influence the work reported in this paper.

\section{Acknowledgements}

The authors are grateful to the Portuguese Foundation of Science and Technology (FCT, Portugal) for financial support through the projects EXCL/AGR-PRO/0591/2012 "Olive crop protection in sustainable production under global climatic changes: linking ecological infrastructures to ecosystem functions" and PTDC/ASP-PLA/30003/ 2017 - "OLIVESIM - Managing ecosystem services in olive groves using advanced landscape agent-based models" and CIMO (UIDB/00690/ 2020). María Villa also thanks to Portuguese Foundation of Science and Technology for the Postdoctoral fellowship SFRH/BPD/119487/2016. The authors would like to thank to the farmers for allowing the access to their olive groves.

\section{Appendix A. Supplementary data}

Supplementary material related to this article can be found, in the online version, at doi:https://doi.org/10.1016/j.agee.2020.106854.

\section{References}

Albertini, A., Pizzolotto, R., Petacchi, R., 2016. Carabid patterns in olive orchards and woody semi-natural habitats: first implication for conservation biological control against Bactrocera oleae. BioControl. https://doi.org/10.1007/s10526-016-9780-x.

Arambourg, Y., 1986. Trait d'entomologie oleicole. Consejo Oleicola Internacional, Madrid.

Bartolini, G., Petruccelli, R., 2002. In: Tindall, H.D., Menini, U.G. (Eds.), Classification, Origin, Diffusion and History of the Olive. Food and Agriculture organization of the United Nations, Rome.

Bento, A., Torres, L., Lopes, J., Pereira, J.A., 2001. Avaliação de prejuízos causados pela traca da oliveira, Prays oleae (Bern.) em Trás-os-Montes. Revta. Cienc. Agrar. 24, 89-96.

Bianchi, F.J.J.A., Booij, C.J.H., Tscharntke, T., 2006. Sustainable pest regulation in agricultural landscapes: a review on landscape composition, biodiversity and natural pest control. Proc. R. Soc. B. 273, 1715-1727. https://doi.org/10.1098/rspb.2006. 3530 .

Boccaccio, L., Petacchi, R., 2009. Landscape effects on the complex of Bactrocera oleae parasitoids and implication for conservation biological control. BioControl. 54, 607-616. https://doi.org/10.1007/s10526-009-9214-0.

Costa, A., Silva, B., Jiménez-Navarro, G., Barreiro, S., Melguizo-Ruiz, Nereida, RodríguezPérez, J., Vasconcelos, S., Beja, P., Moreira, F., Herrera, J.M., 2020. Structural simplification compromises the potential of common insectivorous bats to provide biocontrol services against the major olive pest Pray oleae. Agric. Ecosyst. Environ. 287. https://doi.org/10.1016/j.agee.2019.106708.

Duelli, P., 2001. Lacewings in field crops. In: McEwen, P., New, T.R., Whittington, A.E. (Eds.), Lacewings in the Crop Environment. Cambridge University Press, Cambridge, pp. 158-171.

FAOSTAT, 2019. Food and Agriculture Organization of the United Nations. (Accessed 19/07/2019). http://www.fao.org/faostat/en/\#data/QC.

Fleskens, L., 2007. Conservation Scenarios for Olive Farming on Sloping Land in the Mediterranean. PhD Thesis. Wageningen University, Wageningen. The Netherlands.

Graham, M.H., 2003. Confronting multicollinearity in ecological multiple regression. Ecology. 84, 2809-2815. https://doi.org/10.1890/02-3114.

Hawkes, N.J., Janes, R.W., Heminway, J., Vontas, J., 2005. Detection of resistance-associated point mutations of organophosphate-insensitive acetylcholinesterase in the olive fruit fly, Bactrocera oleae (Gmelin). Pestic. Biochem. Phys. 81 (3), 154-163. https://doi.org/10.1016/j.pestbp.2004.11.003.

IPMA, 2019. Portuguese Institute for Sea and Atmosphere. (Accessed 19/07/2019). https://www.ipma.pt.

Jonsson, M., Straub, C.S., Dibham, R.K., Buckley, H.L., Case, B.S., Hale, R.J., Gratton, C., Wratten, S.D., 2015. Experimental evidence that the effectiveness of conservation biological control depends on landscape complexity. J. Appl. Ecol. 52, 1274-1282. https://doi.org/10.1111/1365-2664.1248.

Koh, I., Holland, J.D., 2015. Grassland plantings and landscape natural areas both influence insect natural enemies. Agric. Ecosyst. Environ. 199, 190-199. https://doi. org/10.1016/j.agee.2014.09.007.

Lefebvre, M., Franck, P., Toubon, J.-F., Bouvier, J.-C., Lavigne, C., 2016. The impact of landscape composition on the occurrence of a canopy dweling spider depends on orchard management. Agric. Ecosyst. Environ. 215, 20-29. https://doi.org/10.1016/ j.agee.2015.09.003.

Martin, E.A., Reineking, B., Seo, B., Steffan-Dewenter, I., 2013. Natural enemy interactions constrain pest control in complex agricultural landscapes. P. Natl. Acad. Sci. U.S.A. 110, 5534-5539. https://doi.org/10.1073/pnas.1215725110.

Martins da Silva, P., Oliveira, J., Ferreira, A., Fonseca, F., Pereira, J.A., Aguiar, C.A.S. Serrano, A.R.M., Sousa, J.P., Santos, S.A.P., 2017. Habitat structure and neighbor linear features influence more carabid functional diversity in olive groves than the farming system. Ecol. Indic. 79, 128-138. https://doi.org/10.1016/j.ecolind.2017. 04.022 .

McGarigal, K., Marks, B.J., 1995. Fragstats. Spatial Pattern Analysis Program for Quantifying Landscape Structure. General Technical Report No PNW-GTR-351. United States Department of Agriculture, Forest Service, Pacific Northwest Research Station, Portland, Oregon.

Montiel Bueno, A., 1981. Factores de regulación de las poblaciones de Prays oleae (Bern.). B. Serv. Plagas. 7, 133-140.

Morente, M., Campos, M., Ruano, F., 2018. Evaluation of two different methods to measure the effects of the management regime on the olive-canopy arthropod community. Agric., Ecosyst. Environ., Appl. Soil Ecol. 259, 111-118. https://doi.org/10. 1016/j.agee.2018.03.003.

Muneret, L., Auriol, A., Thiéry, D., Rusch, A., 2019. Organic farming at local and landscape scales fosters biological pest control in vineyards. Ecol. Appl. 29. https://doi. org/10.1002/eap.1818.

Ortega, M., Pascual, S., 2014. Spatio-temporal analysis of the relationship between landscape structure and the olive fruit fly Bactrocera oleae (Diptera: tephritidae). Agr. Forest Entomol. 16, 14-23. https://doi.org/10.1111/afe.12030.

Ortega, M., Pascual, S., Rescia, A.J., 2016. Spatial structure of olive groves and scrublands affect Bactrocera oleae abundance: a multiscale analysis. Basic Appl. Ecol. 17 696-705. https://doi.org/10.1016/j.baae.2016.06.001.

Paredes, D., Cayuela, L., Campos, M., 2013a. Synergistic effects of ground cover and adjacent vegetation on natural enemies of olive insect pest. Agric., Ecosyst. Environ. Appl. Soil Ecol. 173, 72-80. https://doi.org/10.1016/j.agee.2013.04.016.

Paredes, D., Cayuela, L., Gurr, G., 2013b. Effect of non-crop vegetation types on conservation biological control of pest in olive groves. PeerJ. https://doi.org/10.7717/ peerj.116.

Picchi, M.S., Bocci, G., Petacchi, R., Entling, M.H., 2016. Effects of local and landscape 
factors on spiders and olive fruit flies. Agric. Ecosyst. Environ. 222, 138-147. https:// doi.org/10.1016/j.agee.2016.01.045.

Picchi, M.S., Marchi, S., Abertini, A., Petacchi, R., 2017. Organic management of olive orchards increases the predation rate of overwintering pupae of Bactrocera oleae (Diptera: tephritidae). Biol. Control 108, 9-15. https://doi.org/10.1016/j.biocontrol. 2017.02.002.

Plećaš, M., Gagić, V., Janković, M., Petrović-Obradović, O., Kavallieratos, N.G., Tomanović, Ž., Thies, C., Tscarntke, T., ćetković, A., 2014. Landscape composition and configuration influence cereal aphid-parasitoid-hyperparasitoid interactions and biological control differentially across years. Agric. Ecosyst. Environ. 183, 1-10. https://doi.org/10.1016/j.agee.2013.10.016.

Porcel, M., Andersson, G.K.S., Pålsson, J., Tasin, M., 2018. Organic management in apple orchards:higher impoacts on biological control than on pollination. J. Appl. Ecol. https://doi.org/10.1111/1365-2664.13247.

Poveda, K., Martínez, E., Kersch-Becker, M.F., Bonilla, M.A., Tscharntke, T., 2012. Landscape simplification and altitude affect biodiversity, herbivory and Andean potato yield. J. Appl. Ecol. 49, 513-522. https://doi.org/10.1111/j.1365-2664.2012. 02120.x.

R Core Team, 2018. R: a Language and Environment for Statistical Computing. R Foundation for Statistical Computing, Vienna, Austria. URL: https://www.R-project. org/. (Accessed 25/06/2019).

Rundel, P.W., Arroyo, M.T., Cowling, R.M., Keeley, J.E., Lamont, B.B., Vargas, P., 2016. Mediterranean biomes: evolution of their vegetation, floras, and climate. Annu. Rev. Ecol. Evol. Syst. 47, 383-407.

Sáenz Posada, D.M., 2013. Efecto De La Estructura Del Paisaje En La Polilla Del Olivo Prays Oleae (Lepidoptera: Praydidae). Master Thesis. University Complutense of Madrid.

Samnegårdg, U., Alins, G., Boreux, V., Bosch, J., García, D., Happe, A.-K., Klein, A.-M., Miñarro, M., Mody, M., Porcel, M., Rodrigo, A., Roquer-Benie, L., Tasin, M., Hambäckg, P.A., 2018. Management trade-offs on ecosystem services in apple orchards across Europe: direct and indirect effects of organic production. J. Appl. Ecol. https://doi.org/10.1111/1365-2664.13292.

Teixeira Saturni, F., Jaffe, R., Metzger, J.P., 2016. Landscape structure influence bee community and coffee pollination at different spatial scales. Agric. Ecosyst. Environ. 236, 1-12. https://doi.org/10.1016/j.agee.2016.10.008.

Tous, J., Romero, A., Hermoso, J.F., Ninot, A., 2011. Mediterranean clonal selections evaluated for modern hedgerow olive oil production in Spain. Calif. Agric. (Berkeley)
65, 34-40. https://doi.org/10.3733/ca.v065n01p34.

Tscharntke, T., Klein, A.M., Kruess, A., Steffan-Dewenter, I., Thies, C., 2005. Landscape perspectives on agricultural intensification and biodiversity - ecosystem service management. Ecol. Lett. 8, 857-874. https://doi.org/10.1111/j.1461-0248.2005. 00782.x.

Tscharntke, T., Bommarco, R., Clough, Y., Crist, T.O., Kleijn, D., Rand, T.A., Tylianakis, J.M., Nouhuys, S., Vidal, S., 2007. Conservation biological control and enemy diversity on a landscape scale. Biol. Control 43, 294-309. https://doi.org/10.1016/j. biocontrol.2007.08.006.

Tscharntke, T., Tylianakis, J.M., Rand, T.A., Didham, R.K., Fahrig, L., Batáry, P., Bengtsson, J., Clough, Y., Crist, T.O., Dormann, C.F., Ewers, R.M., Fründ, J., Holt, R.D., Holzschuh, A., Klein, A.M., Kleijn, D., Kremen, C., Landis, D.A., Laurance, W., Lindenmayer, D., Scherber, C., Sodhi, N., Steffan-Dewenter, I., Thies, C., Putten, W.H., Westphal, C., 2012. Landscape moderation of biodiversity patterns and processes - eight hypotheses. Biol. Rev. 87, 661-685. https://doi.org/10.1111/j.1469185X.2011.00216.x.

Tscharntke, T., Karp, D.S., Chaplin-Kramer, R., Batáry, P., DeClerck, F., Gratton, C., Hunt, L., Ives, A., Jonsson, M., Larsen, A., Martin, E.A., Martínez-Salinas, A., Meehan, T.D., O'Rourke, M., Poveda, K., Rosenheim, J.A., Rusch, A., Schellhorn, N., Wanger, T.C., Wratten, S., Zhang, W., 2016. When natural habitat fails to enhance biological pest control - five hypotheses. Biol. Conserv. 204, 449-458. https://doi.org/10.1016/j. biocon.2016.10.001.

Villa, M., Santos, S.A.P., Mexia, A., Bento, A., Pereira, J.A., 2016. Ground cover management affects parasitism of Prays oleae (Bernard). Biol. Control 96, 72-77. https:// doi.org/10.1016/j.biocontrol.2016.01.012.

Wood, S., Scheipl, F., 2016. gamm4: Generalized Additive Mixed Models Using' mgcv' and' lme4'. R Package Version 0.2-4. (Accessed: 01/01/2017). https://CRAN.Rproject.org $/$ package $=$ gamm 4 .

Zhao, Z.H., Reddy, G.V.P., Hui, C., Li, B.L., 2016. Approaches and mechanism for ecologically based pest management across multiple scales. Agric. Ecosyst. Environ. 230, 199-209. https://doi.org/10.1016/j.agee.2016.06.010.

Zuur, A.F., Ieno, E.N., Elphick, C.S., 2010. A protocol for data exploration to avoid common statistical problems. Methods Ecol. Evol. 1, 3-14. https://doi.org/10.1111/ j.2041-210X.2009.00001.x.

Zuur, A.F., Savaliev, A.A., Ieno, E.N., 2014. A Beginner's Guide to Generalized Additive Mixed Models With R. Newburgh. 